American Journal of Applied Sciences 5 (8): 927-933, 2008

ISSN 1546-9239

(C) 2008 Science Publications

\title{
Simulation of Convective Heat-Transfer Coefficient in a Buried Exchanger
}

\author{
${ }^{1}$ Taoufik Mnasri, ${ }^{1}$ Rached Ben Younès, ${ }^{2}$ Maher Raddaoui and ${ }^{1}$ Salem Elouragini \\ ${ }^{1}$ Research Unit of Energy and Environment, University of Gafsa, 2112 Zarroug, Tunisia \\ ${ }^{2}$ IRPHE, UMR 6594 CNRS, Technopôle de Château-Gombert, 13384 Marseille Cedex 13, France
}

\begin{abstract}
This study presents analytical models allowing to study a forced convection laminar flow in non-established dynamic and thermic regimes. We treated a flow in a bitubular exchanger in permanent thermal contact with a semi-infinite medium, such as the ground. The wall temperature as well as the wall heat flux evolve in the course of time until a quasi-steady mode. The theoretical method is original because it uses Green's functions method to determine the analytical solutions of the heat propagation equation on the wall during the heating phase. These analytical solutions allow to identify the temperature distribution versus time. The complexity of the system geometry as well as the infinity of the medium surrounding the exchanger make the traditional methods of numerical resolution unable to solve the problem. We used, to solve it, the finite volume method coupled with the finite element method at the boundary. We studied the effect of Reynolds number, the fluid entry temperature and the transfer duration on the axial evolution of the heat transfer coefficient. We illustrated also the profile of the temperature field in the fluid medium.
\end{abstract}

Key words: Local heat-transfer coefficient, non-established regime, forced convection, exchanger

\section{INTRODUCTION}

The problem of the thermal flow, once the conduct wall is subjected to an imposed temperature or heat flux, interested much the researchers. Among the works relating to this subject, we will quote the works ${ }^{[1,4]}$.

However, the studies, which relate to the nonestablished flow in an annular conduct undergoing an unknown heat flux, through its wall, are $\operatorname{rare}^{[5,8]}$. This type of flow is obtained in the case of heat exchangers.

The problem of the thermal flow, once the conduct wall is subjected to an imposed temperature or heat flux, interested much the researchers. Among the works relating to this subject, we will quote the works ${ }^{[1,4]}$.

However, the studies, which relate to the nonestablished flow in an annular conduct undergoing an unknown heat flux, through its wall, are rare ${ }^{[5,8]}$. This type of flow is obtained in the case of heat exchangers.

A theoric model ${ }^{[5]}$ using the theory of Green's functions ${ }^{[10]}$ and the finite element method on boundary, enables to completely calculate the temperatures evolution of such systems. However, the use of this model requires in any way the precise experimental knowledge of the local coefficient of heat exchange, which is usually impossible because of the difficulty of obtaining precise local measurements. Indeed, several experimental studies were made ${ }^{[11,16]}$, establishing the expression of the local coefficient of transfer, wall-fluid, in correlated or empirical forms.

This present work relates primarily to determinate the heat transfer coefficient of an exchanger in permanent contact with a semi-infinite medium such as the ground. The equations of energy in both parts of the system, solid and fluid, were established and coupled with the continuity relations of temperature and of heat flux at the surface of contact fluid-solid. While basing on the theory of Green's functions, the equation of energy in the solid medium, infinite and tri-dimensional medium (volume of ground), was transformed into an integral equation to be solved in a finite and bidimensional medium (surface of the exchanger). One deduces from it a system of differential and integral equations governing the velocity and temperature fields where the expression of the local coefficient of transfer appears. The finite volume method combined with the finite elements method at the boundary allows a numerical resolution of this system. We deduce from it the various thermal parameters such as the temperature field then the local and average coefficient of heat transfer. One notices an agreement of our model results with the experimental and numerical results of previous works $^{[12,13]}$.

Corresponding Author: Taoufik Mnasri, Research Unit of Energy and Environment, University of Gafsa, 2112 Zarroug, Tunisia 


\section{MATHEMATICAL FORMULATION OF THE PROBLEM}

Our system is a bitubular exchanger composed of two concentric tubes inserted in the soil (Fig. 1). The interior tube is considered thermically insulator.

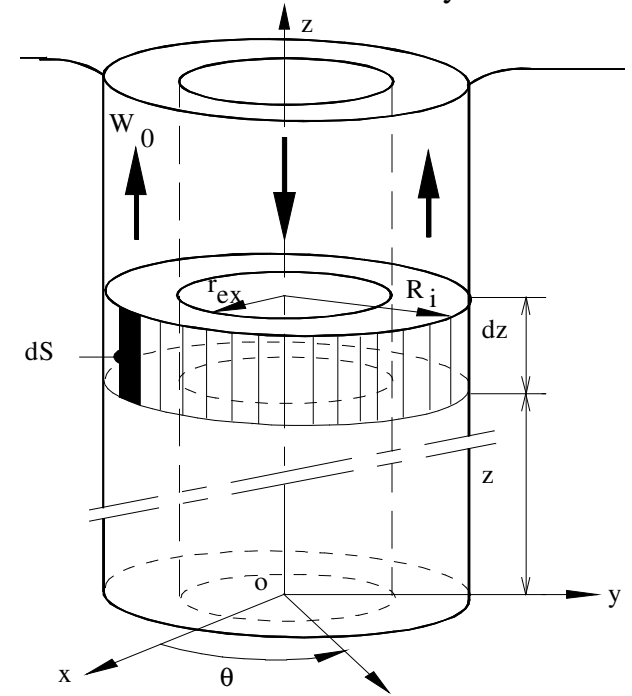

Fig. 1: Geometry of the exchanger

The hot fluid enters the inner tube at temperature $\mathrm{T}_{\mathrm{e}}(\mathrm{t})$, circulates from top to bottom, goes up from base in annular space at average velocity $\mathrm{W}_{0}$ and leaves at an exit temperature $\mathrm{T}_{\mathrm{s}}(\mathrm{t})$.

The medium of storage (ground) constitutes a domain (D) limited by a boundary surface (S). The equation of heat propagation in it is:

$$
\frac{1}{\mathrm{a}_{\text {so }}} \frac{\partial \mathrm{T}(\overrightarrow{\mathrm{r}}, \mathrm{t})}{\partial \mathrm{t}}-\Delta \mathrm{T}(\overrightarrow{\mathrm{r}}, \mathrm{t})=0
$$

The Green function $\mathrm{G}(\overrightarrow{\mathrm{r}}, \overrightarrow{\mathrm{r}}, \mathrm{t})$ is the solution of the associated equation (2):

$$
\frac{1}{\mathrm{a}_{\mathrm{so}}} \frac{\partial \mathrm{G}\left(\overrightarrow{\mathrm{r}}, \overrightarrow{\mathrm{r}}^{\prime}, \mathrm{t}\right)}{\partial \mathrm{t}}-\mathrm{G}\left(\overrightarrow{\mathrm{r}}, \overrightarrow{\mathrm{r}}^{\prime}, \mathrm{t}\right)=\delta\left(\overrightarrow{\mathrm{r}}-\overrightarrow{\mathrm{r}}^{\prime}\right)
$$

$\mathrm{G}(\overrightarrow{\mathrm{r}}, \overrightarrow{\mathrm{r}}, \mathrm{t})$ represents, physically, the response of the medium to a heat impulse on the point $\vec{r}^{\prime}$ at the instant $t=0$. One supposes it is defined in the domain (D), containing the points $\vec{r}$ and $\vec{r}^{\prime}$, limited by surface (S). $G\left(\vec{r}, \vec{r}^{\prime}, t\right)$ is such that it is null for $t<0$ and tends towards $\delta\left(\overrightarrow{\mathrm{r}}, \overrightarrow{\mathrm{r}}, \mathrm{t}^{\prime}\right)$ at $\mathrm{t}=0$.

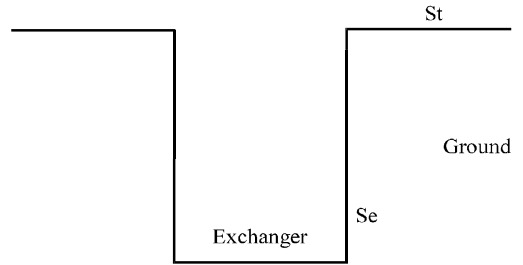

Fig. 2: Boundary surface of the system

The surface (S) of the domain (D) is the reunion of the free surface of the ground $(\mathrm{St})$ and the surface of the buried exchanger $(\mathrm{Se}) ;(\mathrm{S})=(\mathrm{Se}) \cup(\mathrm{St})$ (Fig. 2$)$.

If we apply the Laplace transform to the equations (1) and (2) and we combine them and then we integrate on $\vec{r}$ in the domain (D) limited by surface (S) we obtain:

$$
\begin{aligned}
& \overline{\mathrm{T}}\left(\overrightarrow{\left.\mathrm{r}_{(}^{\prime}, \mathrm{p}\right)}\right)=\iiint_{(\mathrm{D})} \overrightarrow{\mathrm{G}}\left(\overrightarrow{\mathrm{r},}, \overrightarrow{\left.\mathrm{r}^{\prime}, \mathrm{p}\right)} \frac{\mathrm{T}_{0}(\overrightarrow{\mathrm{r}})}{\mathrm{a}_{\text {so }}} \mathrm{d}^{3} \mathrm{r}\right. \\
& +\iint_{(\mathrm{St})}\left[\overrightarrow{\mathrm{G}}\left(\overrightarrow{\mathrm{r}}, \overrightarrow{\mathrm{r}^{\prime}}, \mathrm{p}\right) \vec{\nabla} \mathrm{T}(\overrightarrow{\mathrm{r}}, \mathrm{p})-\mathrm{T}(\overrightarrow{\mathrm{r}}, \mathrm{p}) \vec{\nabla} \overrightarrow{\mathrm{G}}\left(\overrightarrow{\left.\mathrm{r}, \mathrm{r}^{\prime}, \mathrm{p}\right)}\right] \mathrm{nd} \mathrm{S}\right. \\
& +\iint_{(\mathrm{Se})}\left[\vec { \mathrm { G } } \left(\overrightarrow{\left.\mathrm{r}, \mathrm{r}^{\prime}, \mathrm{p}\right)} \vec{\nabla} \mathrm{T}(\overrightarrow{\mathrm{r}}, \mathrm{p})-\mathrm{T}(\overrightarrow{\mathrm{r}}, \mathrm{p}) \vec{\nabla} \overrightarrow{\mathrm{G}}\left(\overrightarrow{\left.\mathrm{r}, \mathrm{r}^{\prime}, \mathrm{p}\right)}\right) \overrightarrow{\mathrm{nd}} \mathrm{S}\right.\right.
\end{aligned}
$$

Going to the original, the temperature of the exchanger surface (wall and base) is relied to the heat flux that escapes at any point from this surface ${ }^{[5,10,17]}$.

$$
\begin{aligned}
\mathrm{T}_{\mathrm{W}}\left(\overrightarrow{\left.\mathrm{r}^{\prime}, \mathrm{t}\right)}\right) & =2 \int_{0}^{\mathrm{t}} \iint_{(\overrightarrow{S e})} \overrightarrow{\mathrm{G}}\left(\overrightarrow{\mathrm{r}}, \overrightarrow{\mathrm{r}^{\prime}, \mathrm{t}}-\tau\right) \vec{\nabla} \mathrm{T}(\overrightarrow{\mathrm{r}}, \tau) \\
& \left.-\mathrm{T}(\overrightarrow{\mathrm{r}, \tau}) \vec{\nabla} \mathrm{G}\left(\overrightarrow{\mathrm{r}}, \overrightarrow{\mathrm{r}^{\prime}, \mathrm{t}}-\tau\right)\right] \overrightarrow{\mathrm{ndSd}} \tau \\
& +2 \overrightarrow{\mathrm{F}}\left(\overrightarrow{\mathrm{r}^{\prime}, \mathrm{t}}\right)
\end{aligned}
$$

where:

$$
\begin{aligned}
\mathrm{F}\left(\overrightarrow{\mathrm{r}}^{\prime}, \mathrm{t}\right) & =\iiint_{(\mathrm{D})} \mathrm{G}\left(\overrightarrow{\mathrm{r}}, \overrightarrow{\mathrm{r}}^{\prime}, \mathrm{t}\right) \frac{\mathrm{T}_{0}(\overrightarrow{\mathrm{r}})}{\mathrm{a}_{\mathrm{so}}} \mathrm{d}^{3} \mathrm{r} \\
& -\int_{0}^{\mathrm{t}} \iint_{(\mathrm{St})} \mathrm{T}(\overrightarrow{\mathrm{r}}, \tau) \vec{\nabla} \mathrm{G}\left(\overrightarrow{\mathrm{r}}, \overrightarrow{\mathrm{r}}^{\prime}, \mathrm{t}-\tau\right) \overrightarrow{\mathrm{n}} \mathrm{dSd} \tau
\end{aligned}
$$

The general solution of the Eq. (2) is the Green function:

$$
G\left(\vec{r}, \vec{r}^{\prime}, t\right)=\frac{a_{s o}}{\left(4 \pi a_{s o} t\right)^{3 / 2}} \exp \left(-\frac{\left(\vec{r}-\vec{r}^{\prime}\right)^{2}}{4 a_{s o} t}\right)
$$

We consider on ( $\mathrm{St}$ ) the case where the surface temperature is imposed and equal to $\mathrm{T}_{\mathrm{a}}(\overrightarrow{\mathrm{r}}, \mathrm{t})$ :

$$
\mathrm{T}(\overrightarrow{\mathrm{r}}, \mathrm{t})_{\mathrm{z}=0}=\mathrm{T}_{\mathrm{a}}(\overrightarrow{\mathrm{r}}, \mathrm{t})
$$


This boundary condition imposes to $G\left(\vec{r}, \vec{r}^{\prime}, t\right)$ to be null on the level of the ground surface (St). We evoke the particular case where the temperature imposed on (St) is equal to the reference temperature $\mathrm{T}_{0}$ supposed as uniform. Consequently, $\mathrm{F}\left(\mathrm{r}^{\prime}, \mathrm{t}\right)$ is null ${ }^{[6]}$.

$$
\mathrm{F}\left(\overrightarrow{\mathrm{r}}^{\prime}, \mathrm{t}\right)=0
$$

We study the case where the contact between the soil and the exchanger is perfect. Consequently, the wall temperature $T_{w}$ is equal to the temperature $T_{f}$, which reigns in the boundary layer of the fluid circulating in the exchanger. The boundary condition on the exchanger surface will be:

$$
\mathrm{T}_{\mathrm{w}}(\overrightarrow{\mathrm{r}}, \mathrm{t})=\mathrm{T}_{\mathrm{f}}(\overrightarrow{\mathrm{r}}, \mathrm{t})_{\text {paroi }}
$$

The quantity of heat yielded by the calorific fluid is completely received by the ground. The density of heat flux, at the wall of the exchanger, is then continuous.

$$
-\mathrm{k}_{\mathrm{f}}\left(\frac{\partial \mathrm{T}_{\mathrm{f}}(\overrightarrow{\mathrm{r}}, \mathrm{t})}{\partial \mathrm{n}}\right)_{\text {paroi }}=-\mathrm{k}_{\mathrm{s}}\left(\frac{\partial \mathrm{T}(\overrightarrow{\mathrm{r}}, \mathrm{t})}{\partial \mathrm{n}}\right)_{\text {paroi }}
$$

If we replace the intervening terms in the relations (9) and (10) in the expression of the temperature at the wall of the relation (4), we obtain:

$$
\begin{aligned}
\mathrm{T}_{\mathrm{w}}\left(\overrightarrow{\mathrm{r}}^{\prime}, \mathrm{t}\right)= & 2 \int_{0}^{\mathrm{t}} \iint_{(\mathrm{Se})}\left[\frac{\mathrm{k}_{\mathrm{f}}}{\mathrm{k}_{\mathrm{s}}} \mathrm{G}\left(\overrightarrow{\mathrm{r}}, \overrightarrow{\mathrm{r}}^{\prime}, \mathrm{t}-\tau\right) \vec{\nabla} \mathrm{T}_{\mathrm{f}}(\overrightarrow{\mathrm{r}}, \tau)\right. \\
& \left.-\mathrm{T}_{\mathrm{f}}(\overrightarrow{\mathrm{r}}, \tau) \vec{\nabla} \mathrm{G}\left(\overrightarrow{\mathrm{r}}, \overrightarrow{\mathrm{r}}^{\prime}, \mathrm{t}-\tau\right)\right] \overrightarrow{\mathrm{n}} \mathrm{dSd} \tau
\end{aligned}
$$

The heat flux density is expressed as:

$$
\Phi=-\mathrm{k}_{\mathrm{f}} \nabla \mathrm{T}_{\mathrm{f}}=\mathrm{h}\left(\mathrm{T}_{\mathrm{f}}-\mathrm{T}_{\mathrm{w}}\right)_{\mathrm{paroi}} \overrightarrow{\mathrm{n}}
$$

We treat the case where $\rho f$ is supposed constant. The axial symmetry of the system (exchanger-fluid) imposes that the flow is plane $(\mathrm{v}=0)$ and bidimensional. Thus the equations, which govern the flow, are written:

$$
\left\{\begin{array}{l}
\frac{\partial \mathrm{u}}{\partial \mathrm{r}}+\frac{\mathrm{u}}{\mathrm{r}}+\frac{\partial \mathrm{w}}{\partial \mathrm{z}}=0 \\
\frac{\partial \mathrm{P}}{\partial \mathrm{r}}=0 \\
\mathrm{u} \frac{\partial \mathrm{w}}{\partial \mathrm{r}}+\mathrm{w} \frac{\partial \mathrm{w}}{\partial \mathrm{z}}=-\frac{1}{\rho_{\mathrm{f}}} \frac{\partial \mathrm{P}^{*}}{\partial \mathrm{z}}+v_{\mathrm{f}}\left[\frac{\partial^{2} \mathrm{w}}{\partial \mathrm{r}^{2}}+\frac{1}{\mathrm{r}} \frac{\partial \mathrm{w}}{\partial \mathrm{r}}\right]
\end{array}\right.
$$

$$
\frac{\partial \mathrm{T}_{\mathrm{f}}}{\partial \mathrm{t}}+\mathrm{u} \frac{\partial \mathrm{T}_{\mathrm{f}}}{\partial \mathrm{r}}+\mathrm{w} \frac{\partial \mathrm{T}_{\mathrm{f}}}{\partial \mathrm{z}}=\mathrm{a}_{\mathrm{f}}\left[\frac{\partial^{2} \mathrm{~T}_{\mathrm{f}}}{\partial \mathrm{r}^{2}}+\frac{1}{\mathrm{r}} \frac{\partial \mathrm{T}_{\mathrm{f}}}{\partial \mathrm{r}}\right]
$$

To simplify the writing, we note in the continuation $\mathrm{T}$ the temperature in any point of the system.

In order to compare with the results presented in the literature, we impose on the entry annular space (on the level of the exchanger base) uniform velocity and temperature fields. For the field velocity and the field temperature the boundary conditions associated with this problem are respectively:

$$
\left\{\begin{array}{l}
u\left(r=R_{i}\right)=u\left(r=r_{e x}\right)=0 \\
w\left(r=R_{i}\right)=w\left(r=r_{e x}\right)=0 \\
u(z=0)=0 \\
w(z=0)=W_{0}
\end{array}\right.
$$

$$
\left\{\begin{array}{l}
\mathrm{T}(\mathrm{r}, \mathrm{z}, 0)=\mathrm{T}_{0} \\
\mathrm{~T}(\mathrm{r}, 0, \mathrm{t})=\mathrm{T}_{\mathrm{e}} \\
\left(\frac{\partial \mathrm{T}}{\partial \mathrm{r}}\right)_{\mathrm{r}=\mathrm{r}_{\mathrm{ex}}}=0 \\
\mathrm{~T}\left(\mathrm{R}_{\mathrm{i}}, \mathrm{z}, \mathrm{t}\right)=2 \int_{0}^{\mathrm{t}} \iint_{(\mathrm{Se})}\left[\frac{\mathrm{k}_{\mathrm{f}}}{\mathrm{k}_{\mathrm{s}} \mathrm{G}(\mathrm{t}-\tau) \vec{\nabla} \mathrm{T}(\tau)}\right. \\
\quad-\mathrm{T}(\tau) \vec{\nabla} \mathrm{G}(\mathrm{t}-\tau)] \overrightarrow{\mathrm{n}} \mathrm{dSd} \tau
\end{array}\right.
$$

If we consider a cross section of the exchanger (Fig. 1), the mean temperature $T_{m}(z, t)$ is the mean of various local temperatures $\mathrm{T}(\mathrm{r}, \mathrm{z}, \mathrm{t})$ on this section.

$$
\mathrm{T}_{\mathrm{m}}(\mathrm{z}, \mathrm{t})=\frac{2}{\mathrm{~W}_{0}\left(\mathrm{R}_{\mathrm{i}}^{2}-\mathrm{r}_{\mathrm{ex}}^{2}\right)} \int_{\mathrm{r}_{\mathrm{ex}}}^{\mathrm{R}} \mathrm{T}(\mathrm{r}, \mathrm{z}, \mathrm{t}) \mathrm{W}(\mathrm{r}, \mathrm{z}) \mathrm{r} \mathrm{dr}
$$

The Eq. (12) enables to express the coefficient $h(z$, t) as follows:

$$
h(z, t)=\frac{\left(k_{f} \frac{\partial T(r, z, t)}{\partial r}\right)_{r=R_{i}}}{\left(T_{w}-T_{m}\right)}
$$




\section{NUMERICAL RESOLUTION}

We profited from the decoupling between the dynamic problem and the thermal problem: The dynamic equations were solved in first stage. However, the discretized energy equations in the fluid zone and on the exchanger surface, were solved in second stage. The equations governing the velocity field were resolved using the finite volume method by adopting the technique of the staggered grid. We use a nonuniform and tight grid near the inner and outer walls to take account of the significant variations of the velocity and the temperature in the zone of the boundary layer. The used grid is of $(30 * 120)$. The coupling pressurevelocity rests on the algorithm Semi-Implicit Method for Pressure Linked Revised (S. I. M. P. L. E. R) ${ }^{[18]}$.

The equations would be integrated on control volume and in interval of time $[t, t+\delta]$. We adopt an implicit diagram for the temporal discretization, which has the advantage of being unconditionally stable. The convective terms are discretized by using an upwind diagram, in order to ensure the stability of the numerical model.

For the discretization of the energy equation on the exchanger surface, the used method is the finite element method at the border ${ }^{[5]}$. It consists in cutting out the exchanger surface in finite annular elements of height $\Delta$. The base alone is considered as an element. Knowing the solution $\mathrm{T}(\mathrm{p} \delta)$ at an instant $\mathrm{p} \delta$; we determine $\mathrm{T}((\mathrm{p}+1) \delta)$ solution at the instant $(\mathrm{p}+1) \delta$. Thus step-by-step from $\mathrm{p}=0$ to $\mathrm{p}=\mathrm{n},(\mathrm{t}=\mathrm{n} \delta)$ we will have the solution. The used discretization schema is an extension of the one adopted by Desmons ${ }^{[5]}$. The stability of this schema was studied by the same author.

The retained iterative method, for the resolution, is the Gauss-Seidel line-by-line method, along the radial axis.

\section{RESULTS AND DISCUSSION}

We determined, numerically, the field of temperature in the system for several combinations of $\operatorname{Re},\left(\mathrm{T}_{\mathrm{e}}-\mathrm{T}_{0}\right) / \mathrm{T}_{0}$ and $\mathrm{t}$.

We represented in the Fig. 3 the field of temperature. The behaviour of the thermal field was, in general, the same for the various combinations. But a precise sight of the results enables us to note that:

The profile of the temperature, uniform at the section of entry, deforms progressively and tends asymptotically towards a profile corresponding to the established thermal regime.

There are two fluid zones: a zone of insulation located near the internal wall where the transfer of heat is negligible and a zone of cooling located near the external wall.

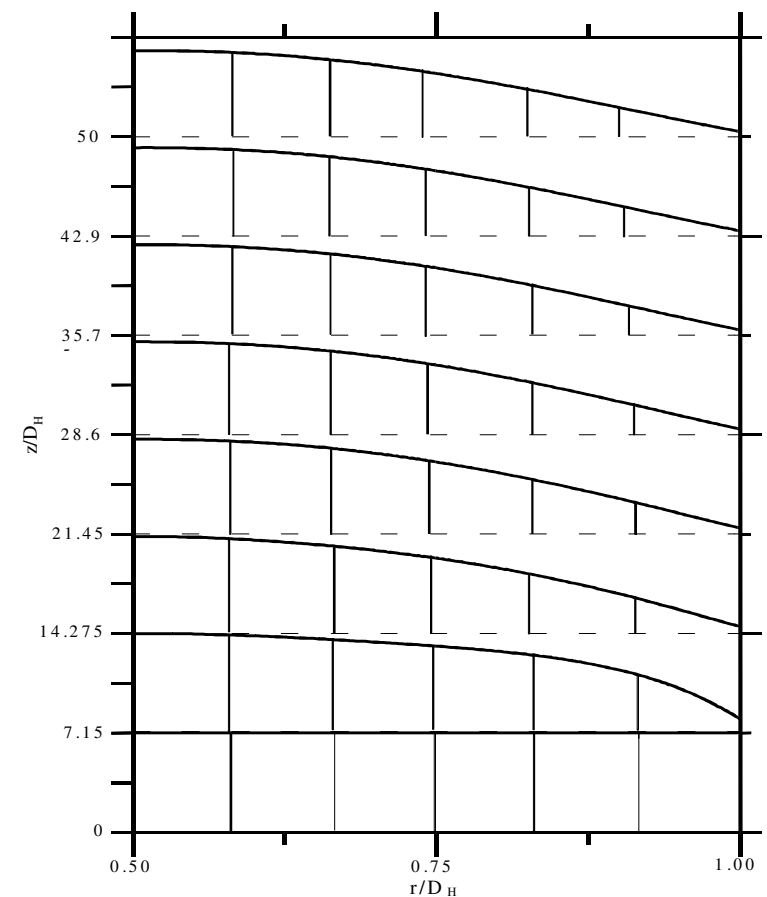

Fig. 3: Profile of the temperature field in the annular space for $\left(\mathrm{T}_{\mathrm{e}}-\mathrm{T}_{0}\right) / \mathrm{T}_{0}=1$ and $\mathrm{Re}=1500$ and for duration of heating $t=240 \mathrm{~s}$

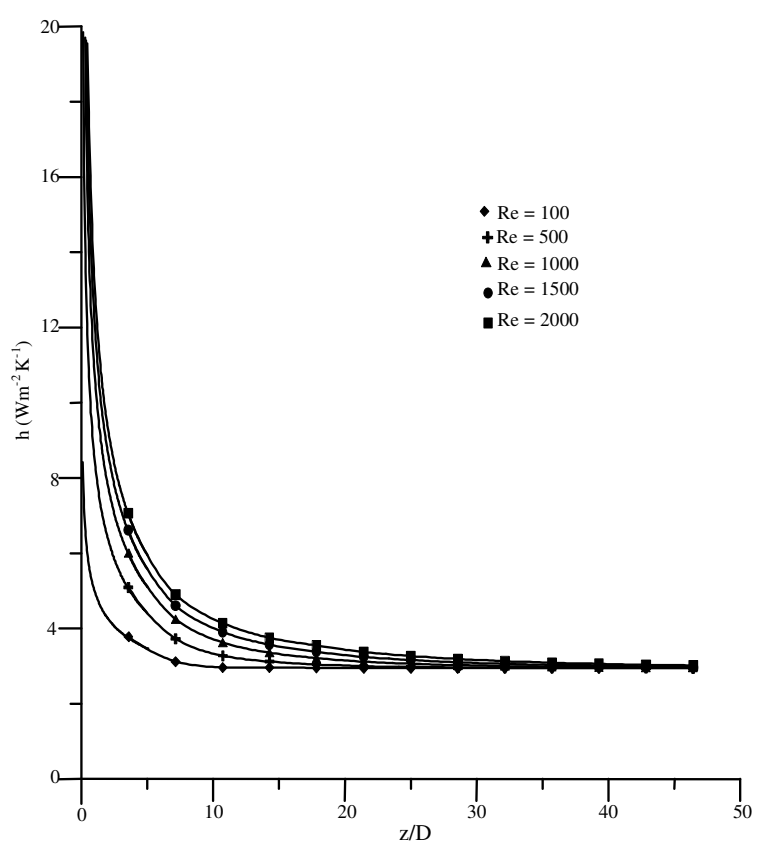

Fig. 4: Variation of the local heat-transfer coefficient for various Reynolds numbers

The coefficient $h$ is independent from $T_{e}$ (for a weak temperature variation where $\rho f$ remains constant); what is confirmed by the correlations based on 


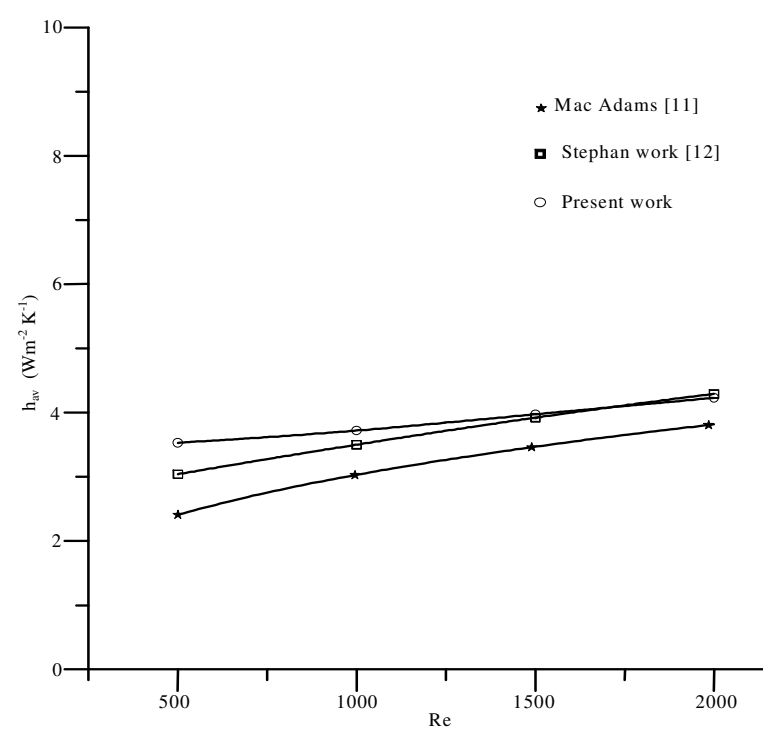

Fig. 5: Variation of the average heat-transfer coefficient versus Reynolds number

experimental data, presented in the literature. In the same way, we checked, numerically, that this transfer coefficient is independent of the heating duration. It is constant and preserves the same value during the unsteady regime.

We determined, numerically, the axial evolution of the transfer local coefficient $\mathrm{h}(\mathrm{z}, \mathrm{Re})$ for $\mathrm{R}_{\mathrm{i}} / \mathrm{r}_{\mathrm{ex}}=2$, $\mathrm{L} / \mathrm{D}_{\mathrm{H}}=50$ and various values of the Reynolds number corresponding to laminar regime $(100 \leq \mathrm{Re} \leq 2500)$, (Fig. 4). We notice that:

For all Re, the curve h ( $\mathrm{z}, \mathrm{Re})$ tends asymptotically towards the value $2.95 \mathrm{~W} / \mathrm{m}^{2} \mathrm{~K}$ (Fig. 4), which is close to the value $2.86 \mathrm{~W} / \mathrm{m}^{2} \mathrm{~K}$ (corresponding to the Nusselt number 4.36 often quoted in most textbooks). This value is obtained for a conductivity $\mathrm{k}_{\mathrm{f}} \approx 0.0262 \mathrm{~W} / \mathrm{mK}$ suitable with the air at the temperature near $300 \mathrm{~K}$ $\left(0.05 \leq\left(\mathrm{T}_{\mathrm{m}}-\mathrm{T}_{0}\right) / \mathrm{T}_{0} \leq 2.5\right), \mathrm{T}_{0}$ being equal to the ambient temperature $\mathrm{T}_{\mathrm{a}}$

$\mathrm{h}(\mathrm{z}, \mathrm{Re})$ can be correlated in the following form:

$$
\mathrm{h}(\mathrm{z}, \mathrm{Re})=\mathrm{A}(\mathrm{z}, \mathrm{Re})\left(\frac{\mathrm{z}}{\mathrm{D}_{\mathrm{H}}}\right)^{-\mathrm{n}(\mathrm{z}, \mathrm{Re})}
$$

We treated in this work the case of a wall, which is not subjected to any of these two conditions. In general, the flux is variable and not uniform during the functioning of the exchanger. It evolves in the course of the time in a significant way at the beginning of the heating operation. However, the mode remains unsteady.

The average value of the transfer coefficient $h$, taken over the whole length of the wall, is correlated under the following equation, valid for $\mathrm{Re} \geq 500$ :

$$
\begin{aligned}
\mathrm{h}_{\mathrm{av}}=\mathrm{h}_{1}+\mathrm{h}_{2}[ & {\left[\frac{\mathrm{D}_{\mathrm{H}}}{\mathrm{L}}\right)^{-0.627+0.107 \ln \mathrm{Re}} } \\
& \left.-60.91\left(\frac{\mathrm{D}_{\mathrm{H}}}{\mathrm{L}}\right) 0.763^{\ln \mathrm{Re}}\right]
\end{aligned}
$$

where:

$h_{1}=\frac{0.264 \operatorname{Re}^{0.31} 0.865^{\ln R e}}{0.941-0.057 \ln \operatorname{Re}} h_{2}=\frac{0.0017 \operatorname{Re}+2.593}{1.627-0.107 \ln \operatorname{Re}}$

We illustrated, in Fig. 5, the transfer average coefficient evolution versus Reynolds numbers. Our results are concordant with those of the previous works: the analysis of uncertainty shows that the error does not exceed $13 \%$ compared to Stephan's results ${ }^{[12,13]}$.

\section{CONCLUSION}

The developed method is able to handle a variable or constant unspecified entry temperature in the course of time. We do not impose any condition between the exchanger and the ground. Thus, we approach the real and practical case for the buried exchangers.

This model enabled us to determine certain significant thermophysical parameters such as the local and average coefficients of heat transfer, the wall temperature and the mean temperature in any point of the axis of the exchanger and in particular at the exit (temperature $\mathrm{T}_{\mathrm{s}}$ ).

In this study, we are concentrated on the validation of our theoretical and numerical model. For that, we considered a particular case of fluid (the air:Pr $\approx 0.7$ ) and for a ratio $\mathrm{L} / \mathrm{D}_{\mathrm{H}}=50$. We will exploit soon this code to generalize our results versus various parameters such as $\mathrm{R}_{\mathrm{i}} / \mathrm{r}_{\mathrm{ex}}, \mathrm{L} / \mathrm{D}_{\mathrm{H}}, \mathrm{Pr}$, etc. It can also be developed for being available in the case of turbulent flows.

\section{ACKNOWLEDGEMENT}

The support of Laboratoire de Mécanique et Energétique (L.M.E) de l'Université de Valenciennes (France) and Institut de Recherche sur les Phénomènes Hors Equilibre (I.R.P.H.E), UMR 6594 CNRS, Marseille (France) is gratefully acknowledged. The 
authors wish also to thank Mr. J. Y. Desmons and R. Schiestel for their generous helps.

\section{NOMENCLATURE}

\begin{tabular}{|c|c|}
\hline$a_{\mathrm{so}}$ & $=$ diffusivity of the ground, $\mathrm{m}^{2} / \mathrm{s}$ \\
\hline$a_{f}$ & $=$ diffusivity of the fluid, $\mathrm{m}^{2} / \mathrm{s}$ \\
\hline $\mathrm{D}$ & $=$ domain of storage \\
\hline $\mathrm{D}_{\mathrm{H}}$ & $=$ hydraulic diameter, $\left[2\left(\mathrm{R}_{\mathrm{i}}-\mathrm{r}_{\mathrm{ex}}\right)\right], \mathrm{m}$ \\
\hline $\mathrm{G}\left(\overrightarrow{\mathrm{r}}, \overrightarrow{\mathrm{r}^{\prime}}, \mathrm{t}\right)$ & $=$ Green's function \\
\hline h & $\begin{array}{l}=\text { local convective transfer coefficient } \\
=\text { at the wall, } \mathrm{W} / \mathrm{m}^{2} \mathrm{~K}\end{array}$ \\
\hline $\mathrm{h}_{\mathrm{av}}$ & $\begin{aligned}= & \text { average convective transfer } \\
& \text { coefficient at the wall, } \mathrm{W} / \mathrm{m}^{2} \mathrm{~K}\end{aligned}$ \\
\hline $\mathrm{k}_{\mathrm{f}}$ & $\begin{array}{l}=\text { thermal conductivity of the fluid, } \\
\mathrm{W} / \mathrm{mK}\end{array}$ \\
\hline $\mathrm{k}_{\mathrm{s}}$ & $\begin{array}{l}=\text { thermal conductivity of the soil, } \\
\mathrm{W} / \mathrm{mK}\end{array}$ \\
\hline $\mathrm{L}$ & $=$ length of the exchanger, $\mathrm{m}$ \\
\hline $\overrightarrow{\mathrm{n}}$ & $\begin{aligned} &= \text { unit vector of the outer normal at the } \\
& \text { point } \overrightarrow{\mathrm{r}} \text { on surface }(\mathrm{S})\end{aligned}$ \\
\hline $\mathrm{P}^{*}$ & $=$ Dynamic fluid pressure, $\mathrm{Pa}$ \\
\hline $\overrightarrow{\mathrm{r}}(\mathrm{x}, \mathrm{y}, \mathrm{z})$ & $=$ vector-position in the space \\
\hline $\overrightarrow{\mathrm{r}}^{\prime}\left(\mathrm{x}^{\prime}, \mathrm{y}^{\prime}, \mathrm{z}^{\prime}\right)$ & $\begin{array}{l}=\text { vector-position in the space where } \\
\text { the temperature is evaluated }\end{array}$ \\
\hline$r_{\mathrm{ex}}$ & $=$ outer radius of the central tube, $\mathrm{m}$ \\
\hline $\mathrm{R}_{\mathrm{i}}$ & $=$ inner radius of the exchanger, $\mathrm{m}$ \\
\hline & $=$ boundary surface of storage domain, \\
\hline $\mathrm{Se}$ & $=$ exchanger surface, $\mathrm{m}^{2}$ \\
\hline St & $=$ free surface of the ground, $\mathrm{m}^{2}$ \\
\hline $\mathrm{t}$ & $=$ time, $\mathrm{s}$ \\
\hline $\mathrm{T}(\overrightarrow{\mathrm{r}}, \mathrm{t})$ & $\begin{aligned}= & \text { temperature at point } \overrightarrow{\mathrm{r}} \text { at the instant } \\
& \mathrm{t}, \mathrm{K}\end{aligned}$ \\
\hline $\mathrm{T}_{\mathrm{a}}(\overrightarrow{\mathrm{r}}, \mathrm{t})$ & $=$ ambient temperature, $\mathrm{K}$ \\
\hline $\mathrm{T}_{\mathrm{e}}$ & $\begin{array}{l}=\text { entry temperature of the fluid in the } \\
\text { inner tube, } \mathrm{K}\end{array}$ \\
\hline $\mathrm{T}_{\mathrm{m}}$ & $\begin{array}{l}=\text { mean temperature of the fluid in } \\
\text { annular space at height } \mathrm{z} \text { and } \\
\text { moment } \mathrm{t}, \mathrm{K}\end{array}$ \\
\hline $\mathrm{T}_{\mathrm{w}}\left(\overrightarrow{\mathrm{r}}^{\prime}, \mathrm{t}\right)$ & $\begin{array}{l}=\text { temperature of the exchanger wall at } \\
=\text { height } \mathrm{z} \text { and moment } \mathrm{t}, \mathrm{K}\end{array}$ \\
\hline $\mathrm{T}_{0}(\overrightarrow{\mathrm{r}})$ & $\begin{aligned}= & \text { initial temperature field in the } \\
& \text { ground } \mathrm{T}(\overrightarrow{\mathrm{r}}, \mathrm{t}=0), \mathrm{K}\end{aligned}$ \\
\hline $\mathrm{u}$ & $=$ radial velocity, $\mathrm{m} / \mathrm{s}$ \\
\hline $\mathrm{v}$ & $=$ orthoradial velocity, $\mathrm{m} / \mathrm{s}$ \\
\hline $\mathrm{w}$ & $=$ axial velocity in annular space, $\mathrm{m} / \mathrm{s}$ \\
\hline $\mathrm{W}_{0}$ & $\begin{aligned}= & \text { average velocity of fluid in annular } \\
& \text { space, } \mathrm{m} / \mathrm{s}\end{aligned}$ \\
\hline $\mathrm{Z}$ & $=$ axial coordinate, $\mathrm{m}$ \\
\hline
\end{tabular}

\section{Greek symbols}

$\delta \quad=$ time step, $\mathrm{s}$

$\Delta \mathrm{r} \quad=$ radial width of the control volume, $\mathrm{m}$

$\Delta \mathrm{z} \quad=\mathrm{z}$-direction width of the control volume, $\mathbf{m}$

$\Phi=$ heat flux density, $\mathrm{W} / \mathrm{m}$

vf $\quad=$ cinematic viscosity of the fluid, $\mathrm{m}^{2} / \mathrm{s}$

of $\quad=$ fluid density, $\mathrm{kg} / \mathrm{m}$

$\tau=$ variable of integration of time, $\mathrm{s}$

$\theta \quad=$ polar angle

\section{Subscripts}

a = ambient

av = average

e $\quad=$ entry of the exchanger

$\mathrm{f} \quad$ = fluid

ex $=$ outer of the central tube

$\mathrm{H} \quad$ = hydraulic

$\mathrm{i} \quad=$ inner of the exchanger

$\mathrm{m} \quad=$ mean

$\mathrm{W} \quad=$ exchanger wall

$0 \quad=$ Initial

Non-dimensional numbers

$\operatorname{Pr}$

$=$ Prandtl number

Re $\quad=$ Reynolds number, $\left[\mathrm{W}_{0} \mathrm{D}_{\mathrm{H \rho f}} / \mu\right)$

\section{REFERENCES}

1. Jones, A.S., 1971. Extension to the solution of the Gratez problem: Int. J. Heat Mass Transfer, 14: 619-623.

2. Hatton, A.P. and A. Quarmby, 1962. Heat transfer in the thermal entry length with laminar flow in an annulus: Int. J. Heat Mass Transfer, 5: 973-980.

3. Mojtabi, A. and J.P. Caltagirone, 1978. Convection entre deux cylindres coaxiaux en régime laminaire permanent: Int. J. Heat Mass Transfer, 21: 261-268.

4. Murakawa, K., 1961. Heat transfer in entry length of double pipes: Int. J. Heat Mass Transfer, 2: 240-251.

5. Desmons, J.Y., 1984. Formulation et résolution numérique de problèmes aux limites appliquées aux générateurs de chaleurs tubulaires enterrées: Thèse de Doctorat d'Etat, Université de Valenciennes.

6. Desmons, J.Y. and R. Ben Younès, 1997. Prévision à long terme de la réponse d'un stockage de chaleur sensible dans le sol : Int. J. Heat Mass Transfer, 40: 3119-3134. 
7. Stevens, J.W., 2002. Coupled conduction and intermittent convective heat transfer from a buried pipe: Heat Transfer Engineering, 23: 34-43.

8. Mnasri, T., R. Ben Younes, A. Mazioud and J.F. Durastanti, 2007. Etude du cefficient de transfert d'un échangeur bi-tubulaire enterré en régime instationnaire : Congrès français de thermique (SFT), Ile des Embiez, Tome, 1: 361-366.

9. Mnasri, T., R. Ben Younès, M. Raddaoui and S. Elouragini, 2007. Convective heat-transfer coefficient in a buried bi-tubular exchanger -Use of Green's functions theory-Proceedings of the Third Int. Conf. on Thermal Engineering: Theory and Applications, Amman, Jordan.

10. Carslaw, H.S. and J.C. Jager, 1959. Conduction of heat in solids: Oxford University Press. London.

11. Mac Adams, W.H., 1954. Transmission de la chaleur: McGraw Hill. New York.

12. Stephan, K., 1959. Wärmeübergang und Druckabfall bei nicht ausgebildeter Laminarströmung in Rohren und ebenen Spalten: Chemie-lngenieur-Technik, 31: 773-778.
13. Mnasri, T. and R. BenYounès, 2007. Convective heat transfer coefficient in a buried bitubular exchanger in transitory flow: Article accepted in Phys. and Chem. News for publication.

14. Quarmby, A., 1967. Some measurements of turbulent heat transfer in the thermal entrance region of concentric annuli: Int. J. Heat Mass Transfer, 10: 267-276.

15. Baudoin, A., M. Abgrall and J.P. Padet, 1990. Etude d'un échangeur baïonnette en milieu solide infini : Rev. Générale de Thermique, 348: 700-707.

15. Dirker, J. and J. Meyer, 2005. Convective Heat Transfer Coefficients in Concentric Annuli: Heat Transfer Engineering, 26: 38-44.

17. BenYounès, R., 1993. Prévision numérique et expérimentale de la réponse intrinsèque d'un échangeur bitubulaire enterré en régime continu: Thèse de Doctorat, Université de Valenciennes.

18. Patankar, S.V., 1980. Numerical heat transfer and fluid flow: McGraw Hill, Serie in computational methods in mechanics and thermal sciences. New York. 